

\title{
Class or location? \\ What explains the rising tide of absolute global income inequality during 1850-2010?
}

\author{
Thomas Goda ${ }^{a}$ and Alejandro Torres ${ }^{b}$
}

March 2015

\begin{abstract}
This paper is the first to decompose absolute global income inequality into its within-country -class - and between-country - location-components. The estimates show that until 1970 locational income differences were the main driver of absolute global inequality, whereas its recent growth can be explained primarily by class differences. Nowadays, inequality between classes explains $70 \%$ of absolute global market inequality. Additional findings are that absolute income convergence between countries took place after 2005, that it is possible to reduce absolute inequality and to grow at the same time, and that of late within countries net inequality was growing faster than market inequality.
\end{abstract}

Key Words: absolute inequality, personal income distribution, global inequality, withincountry inequality, between-country inequality, class

JEL Classification: D31; D63; O15

\footnotetext{
${ }^{a}$ Universidad EAFIT, School of Economics and Finance, Carrera 49 Número 7 Sur 50, Medellín, Colombia; e-mail: tgoda@eafit.edu.co; phone: (57) 42619500 - 8664; fax: (57) 42619294 (corresponding author)

${ }^{\mathrm{b}}$ Universidad EAFIT, School of Economics and Finance, Carrera 49 Número 7 Sur 50, Medellín, Colombia; e-mail: atorres7@eafit.edu.co.

We thank Angélica Sanchez, Juliana Arias, and Natalia Gaviria for their outstanding research assistance. Furthermore, we are grateful to Bas van Leeuwen (and his co-authors) for providing us with an updated version of their historic Gini coefficient database based on their paper The Changing Shape of Global Inequality 1850-2000. We also would like to thank Maria Fernanda Quintero, Gustavo Canavire, Thedore Breton, and the participants of the 18th annual conference of the Research Network Macroeconomics and Macroeconomic Policies (FMM) for their helpful comments that helped us to improve this paper.
} 


\section{Introduction}

Existing research suggests that income inequality can have adverse effects on social justice and economic growth (Persson and Tabellini, 1994; Sen, 2000; Picket and Wilkinson, 2010; Herzer and Vollmer, 2012; 2013; Halter et al., 2014; Onaran and Galanis, 2014; Kumhof et al., 2015), and of late the popular perception that globalization is not leading to "a rising tide that lifts all boats" is growing. Accordingly, politicians, academics and the media frequently state that inequality is one of the biggest challenges of our time and that the topic demands much more attention (Obama, 2011; Krueger, 2012; Minton Beddoes, 2012; Shiller, 2012; Stiglitz, 2012; Lagarde, 2013; Piketty, 2015).

Empirical studies that examine the global evolution of income inequality almost exclusively concentrate on relative inequality (e.g. Milanovic, 2005; 2013; Sala-i-Martin, 2006; Piketty, 2014; van Zanden et al., 2014). However, inequality can also be measured in absolute terms. Contrary to relative inequality, absolute inequality depends on changes in the absolute differences of income between citizens or countries, and can widen even though proportionate income difference stay constant. If, for example, the income of the whole population increases by the same percentage relative income differences stay constant but the gap in absolute monetary terms grows. ${ }^{1}$

Several authors argue that the focus on relative inequality is unduly restrictive (Ravallion, 2004; Svedberg, 2004; Atkinson and Brandolini, 2010, Bosmans et al., 2014; Anand and Segal, 2014). Surveys show that people often refer to absolute income differences when they talk about inequality (Ballano and Ruiz-Castillo, 1993; Harrison and Seidel, 1994; Amiel and Cowell, 1999) and there is "little obvious reason for assuming that it is the relative inequalities in incomes (rather than absolute inequalities) that matter instrumentally to valued social outcomes" (Ravallion, 2004, pg.19). Indeed, differences in perceptions in part explains why conflicting views about the distributional outcomes of globalisation exist — depending on whether people refer to absolute or relative inequality they claim that globalisation leads to less or more inequality (Ravallion, 2004; Atkinson and Brandolini, 2010). Moreover, previous studies suggest

\footnotetext{
${ }^{1}$ Suppose that a country has two citizens that have an income of $\$ 1,000(\mathrm{~A})$ and $\$ 100,000(\mathrm{~B})$. If the income of both grows by $10 \%$, the new income of citizen $\mathrm{A}$ is $\$ 1,100$ and that of citizen $\mathrm{B}$ is $\$ 110,000$. The proportional income difference between the two stayed constant (B has still 100 times more income than A) but the absolute gap between the two incomes increased by $\$ 9,900$.
} 
that absolute inequality (i) increases the tendency that crimes are committed, given that the expected value of delinquency increases (Fleisher, 1966; Ehrlich, 1973), (ii) augments the potential lobbying power of the elites and therefore is likely to influence democratic decision processes (see Esteban and Ray, 2006; Acemoglu and Robinson, 2008; Gilens and Page, 2014), and (iii) affects the demand for assets and thus influence their prices (Froud et al., 2001; Goda and Lysandrou, 2014). ${ }^{2}$

The few papers that present data about absolute income changes unanimously report a sharp increase in between-country and global inequality. ${ }^{3}$ Pritchett $(1997$, p.11) reports that the average difference between the GDP per capita of the seven richest countries and that of least developed countries increased from around 1,000 to around 11,500 constant international dollars between 1870 and 1990, and Bosmans et al.'s (2014) estimates suggest that this trend continued between 1990 and 2005. With regard to global inequality, Dikhanov and Ward (2002, Table 2) show that the absolute income difference between an average person in the bottom and top decile grew from around 19,000 to around 29,000 between 1970 and 1999. This finding is in line with Atkinson and Brandolini's (2010) and Anand and Segal's (2014) estimations, which demonstrate that absolute global inequality increased continuously between 1820 and 2005 .

To date, no absolute inequality study has measured within-country inequality trends on a global scale. It is therefore not clear if the reported increase in absolute global inequality was mainly driven by growing inequalities within or between countries. The mayor aim of our paper is to show how absolute global within-country and between-country inequality evolved during the period 1850 to 2010, to close this gap in the literature. Moreover, this is the first absolute inequality study that compares changes in net and market inequality ${ }^{4}$ and that takes different purchasing power parity (PPP) exchange rates into account.

As pointed out by Anand and Segal (2014, pg.1), the decomposition of global inequality is important as it "is at least a necessary precursor to any causal explanation because one would expect different mechanisms to explain the two components". A further reason why such a

\footnotetext{
2 Please note also that, from a technical point of view, absolute indices are as good inequality measures as relative indices (see Kolm, 1976).

${ }^{3}$ When inequality is measured across countries three concepts are typically used: within-country, between-country and global inequality. The first concept refer to inequalities within the border of a country, the second concept to differences in the GDP per capita between countries, and the third concept to worldwide inequalities between individuals irrespective of their country of residence.

${ }^{4}$ Market income is pre-tax and pre-transfer income, while net income considers tax payments and transfer receipts.
} 
decomposition is of interest is that it shows whether global inequality is mainly driven by income differences between 'locations' or between 'classes'. Between-country inequality can be called "'locational' because it depends on the differences of mean incomes between various places (countries), and the within inequality, 'class' inequality because it depends on different individuals, living in the same country, having different incomes" (Milanovic, 2012a; pg. 127). ${ }^{5}$ This distinction has important policy implications: if one intends to reduce global inequality migration would be a very efficient policy when inequalities between locations mainly explain global income differences (Milanovic, 2012a, 2013), whereas redistribution between rich and poor citizens would be the best policy option when inequality is mainly driven by class differences.

Our findings provide evidence that until 1970 locational income differences were the main driver of absolute global inequality, whereas most of its recent growth can be explained by class income differences. In 2010 the class component explained 70\% of absolute global market income inequality and around $60 \%$ of absolute global net income inequality. Additionally, we find that absolute income convergence between countries took place after 2005 (for the first time since 1850), that it is possible to reduce absolute inequality and to grow at the same time, and that within countries net inequality was growing faster than market inequality between 1995 and 2010. These results are robust regardless of the PPP exchange rate used.

The layout of this paper is as follows. Section two gives details of the model specification and the data used. Section three presents and discusses the estimation results. Section four concludes.

\section{Model specification and the data used}

An inequality index $I_{A}: R \rightarrow R^{1}$ is an absolute index if it stays constant when all incomes change by the same absolute amount (Chakravarty, 2001; Chakravarty and Tyagarupananda, 2009). That is, for all $n \in N$ and for all $x \in R^{n}$ :

\footnotetext{
${ }^{5}$ The term 'class' often is used to distinguish between social groups, like workers, capitalists, managers, rentiers, proletariat, ruling class, etc. The justification to use the term class as synonym for income classes is that "the concept of class [is also widely used to describe] a collection of individuals sharing similar economic circumstances" (Encyclopædia Britannica, 2015).
} 


$$
I_{A}^{n}=I_{A}^{n}\left(x+c 1^{n}\right)
$$

where $c>0$ is any scalar and 1 is a vector of ones of dimension $n$.

Atkinson and Brandolini (2010) and Anand and Segal (2014) use the Absolute Gini Index to measure changes in absolute global inequality. ${ }^{6}$ This inequality measure fulfils the Symmetry property (SYM), the Population Principle (POP), the Normalization property (NOM), and the Principle of Transfers (POT) ${ }^{7}$. Additionally, it is has the advantage that it transforms in the most widely used relative inequality measure - the Gini Index - when it is normalized by the mean income.

The Absolute Gini Index is not Subgroup Decomposable (SUD) though. To satisfy SUD an index needs to report values that are completely decomposable into within-group and betweengroup inequality. Given that we want to decompose global inequality into its within- and between-country components this property is very important for our purpose. According to Chakravarty (2001) and Chakravarty and Tyagarupananda (2009), an absolute inequality index $\left(I_{A}\right)$ that fulfills the SUD property can be expressed as follows:

$$
I_{A}^{n}(x)=\sum_{i=1}^{k} \omega(\underline{n}, \underline{\lambda}) I^{n_{i}}\left(x^{i}\right)+I^{n}\left(\lambda_{1} 1^{n_{1}}, \ldots, \lambda_{k} 1^{n_{k}}\right)
$$

where $k \geq 2$ denote the number of subgroups used; $n_{i}$ is the population size associated with the distribution $x_{i}, n=\sum_{i=1}^{k} n_{i}, \lambda_{i}=$ mean of distribution $x_{i}, \underline{\lambda}=\left(\lambda^{1}, \lambda^{2} \ldots \lambda^{k}\right), \underline{n}=\left(n^{1}, n^{2} \ldots n^{k}\right)$ and $\omega_{i}(\underline{n}, \underline{\lambda})$ is the positive weight attached to inequality in $x_{i}$, assumed to depend of $\underline{n}$ and $\underline{\lambda}$. The first part of Equation 2 represents within-group inequality and the second part betweengroup inequality.

To estimate the level of inequality between individuals around the globe it is crucial to take countries' population sizes into account (which means that $\omega_{i}(\underline{n}, \underline{\lambda})=n_{i} / n$.). Hence, an index also needs to be Population Share Weighted Decomposable (PSD) to be suitable for our purpose.

\footnotetext{
${ }^{6}$ Anand and Segal (2014) also use the absolute Theil $\mathrm{L}$ and Theil $\mathrm{T}$ index. Both indices report the same trend changes as the absolute Gini index.

${ }^{7}$ SYM means that the index is invariant to the reordering of incomes. POP means that the value of the index does not depend on the population size. NOM means that the index is non-negative and that it has the value of zero only under the condition that all incomes are equal. POT means that an index reports decreasing inequality when a transfer of income from a rich person to a poor person occurs (when this transfer does not change the relative income position of the two persons).
} 
Chakravarty (2001) and Chakravarty and Tyagarupananda (2009) demonstrate that the only absolute inequality index that satisfies PSD, SYM, NOM and POT is a positive multiple of the variance:

$$
I_{V}^{n}(x)=\frac{1}{N} \sum_{i=1}^{n}\left(x_{i}-\lambda\right)^{2}
$$

The variance can be seen as a special case of the class of absolute decomposable indices of inequality as it attaches equal weight to a transfer from a rich to a poor person at all income positions (Bosmans and Cowell, 2010). ${ }^{8}$ The variance also has the advantage that it is easy to compute because its components are independent of each other. ${ }^{9}$ Hence, the variance is the most suitable inequality measure for our purpose, and the specific form of our absolute global inequality index is:

$$
=\sum_{i=1}^{k} \frac{n_{i}}{N}\left(\frac{1}{20} \sum_{p=1}^{20}\left(\left(x_{i p} * G D P_{i}\right)-G D P p c_{i}\right)^{2}\right)+\frac{1}{N}\left(\sum_{i=1}^{k} n_{i}\left(G D P p c_{i}-G D P p c w\right)^{2}\right)
$$

where $k$ is the number of countries included in the measure, $n_{i}$ denotes the population size of the $i$-th country, $N=\sum_{i=1}^{k} n_{i}$ is the global population, $x_{i p}$ is the income share of the $p$-th population ventile $^{10}$ of the $i$-th country, GDP $P_{i}$ is the total income of the $i$-th country; GDP $p c i$ the mean (per capita) income of the $i$-th country and GDPpcw the mean income of the world, weighted by population. The first part of this index shows class inequality and the second part locational income differences.

To estimate the second part of Equation 4, we put together a dataset that contains each country's constant GDP per capita in $\mathrm{PPP}^{11}$ and population size. Due to data availability this dataset is based on two series: one historical series for the period 1850 to 1980 and one recent series from 1980 to 2010. The data are retrieved from Maddison Project's (2013) database and

\footnotetext{
${ }^{8}$ Technically speaking, the variance is a special case of the class of absolute decomposable inequality measure when the real number associated at the index is $\mathrm{c}=0$ - see Bosmans and Cowell (2010) for a demonstration.

${ }^{9}$ This means that the variance is the absolute counterpart of the Mean Logarithmic Deviation (MLD), which is the only relative inequality index that satisfies the PSD property (see Shorrocks, 1980).

${ }^{10}$ Ventile shares are frequently used in the literature as they allow for relatively exact inequality estimates when income differences within income share groups are not taken into account (see Davies and Shorrocks, 1989; Milanovic, 2012). Each population ventile represent $5 \%$ of the population. The ordering and grouping of the population takes place according to their income (the lowest ventile represents the poorest $5 \%$ of the population etc.). Please note that our results are robust when decile or quintile shares are used instead of ventile shares.

${ }^{11}$ It is a common procedure among global inequality studies to use GDP per capita in PPP and not in market exchange rates (see Anand and Segal (2008) for a discussion of the reasons).
} 
World Bank's World Development Indicators (WDI). To ensure relative consistent estimates between the historical and recent data series, most of our analysis in the next section is based on Maddison Project's GDP per capita data in 1990 PPP. Additional reasons to concentrate mainly on these data are that the 2005 PPP estimates have been heavily criticized (see e.g. Deaton and Heston, 2010; Breton and García, 2015), and that the new 2011 PPP estimates apparently are relatively similar to the pre-2005 estimates (see Deaton and Aten, 2014). To check for the robustness of our results when different PPP exchange rates are used, we also present estimates using 2005 and 2011 PPP exchange rates (see Section 3.3).

To calculate the within-country component we also need income shares for each country (see part one of Equation 4). Unfortunately, for most countries these data are not readily available. To solve this issue, we follow van Zanden et al. (2014) to calculate the income shares of the $p$-th percentile $\left(x_{i p}\right)$ :

$$
x_{i p}=\Phi\left(\Phi^{-1}\left(p_{i j}\right)-\sigma_{i}\right)
$$

where $\Phi$ is the cumulative distribution function of income ${ }^{12}$ and $\sigma_{i}$ the standard deviation of the Gini coefficient of each country and year under study.

The standard deviation is calculated as follows:

$$
\sigma_{i}=\sqrt{2 \Phi^{-1}}\left(\frac{1+G_{i}}{2}\right)
$$

where $G_{i}$ is the Gini coefficient. Please note that that this method produces estimates that overall fit the 'real' data very well (see Appendix).

The Gini coefficients for the historical series were kindly provided by Bas van Leeuwen and are based on the paper van Zanden et al. (2014). At the time of writing this dataset was not only the broadest available but also the one that presented the most consistent estimates of historical Gini coefficients. Van Zanden et al. (2014) report market income Gini coefficients in 20 year intervals for the period 1850 and 1950 and in five year intervals afterwards. Given that not for all

\footnotetext{
${ }^{12}$ We use a lognormal distribution because "the literature suggests that when the whole distribution is covered, the log-normal is to be preferred [and] on average the difference between an assumed log-normal and a Pareto distribution [is] limited" (van Zanden et al., 2014, pp.4-5 of their data appendix; see also Soltow (1998) and Lopez and Servén (2006)).
} 
countries data are available in five year intervals, we use ten year intervals between 1950 and 1980 to maximize the number of countries that have data for all years under consideration.

The Gini coefficients for the recent series were retrieved from Solt's Standardized World Income Inequality Database (SWIID) (2013, version 4.0). This database is widely used and has the advantage that it "provides comparable Gini indices of gross and net income inequality for 153 countries for as many years as possible [and therefore] is better suited to broad crossnational research on income inequality than previously available sources" (Solt, 2009, pg. 231). Given that the SWIID does not provide data for every country in each year, we are using a five-year benchmark methodology that is similar to Milanovic's $(2005 ; 2012 b)$ approach. ${ }^{13}$

Table 1 summarizes the data availability and the data sources. The available data are very unbalanced: the minimum amount of countries for which population, GDP per capita and Gini data are available is 32 (year 1850) and the maximum amount is 140 (year 2005). If one would use the whole sample for the estimates, the results could be influenced by the inclusion/exclusion of different countries in different years. We therefore base our main estimates on a core group of 29 countries $^{14}$, for which all data are available in all years ${ }^{15}$. This core group of countries is very representative - on average, it represents $76 \%$ of the global population and $88 \%$ of the global GDP — but is handicapped by the non-inclusion of African countries. However, our overall results are not affected by this shortcoming (see Section 3.3).

\footnotetext{
${ }^{13}$ When Solt's database reports a Gini coefficient for a country in a benchmark year this coefficient is taken for that year. Otherwise, we are using either the Gini coefficient that was reported one year before or one year after the respective benchmark year; or, when data for both are available, the simple mean of the these two Gini coefficients.

${ }^{14}$ Australia, Belgium, Brazil, Canada, Chile, China, Colombia, Czechoslovakia, Denmark, France, Germany, India, Indonesia, Ireland, Italy, Japan, Mexico, Netherlands, Norway, Peru, Philippines, Poland, Portugal, Russia, Spain, Sweden, Switzerland, Thailand, United Kingdom, United States.

15 To ensure a maximum amount of core countries we imputed some data (see Table A3 in the Appendix).
} 
Table 1: Data sources and number of countries with available data

\begin{tabular}{|cccccccc|}
\hline Year & \multicolumn{2}{c}{ Population } & \multicolumn{2}{c}{ GDP per capita (1990 PPP) } & \multicolumn{2}{c|}{ Gini } & \multicolumn{2}{c|}{ All three variables } \\
& \# countries & source & \# countries & source & \# countries & source & \# countries \\
\hline $\mathbf{1 8 5 0}$ & 67 & Maddison & 44 & Maddison & 47 & van Zanden & $\mathbf{3 2}$ \\
$\mathbf{1 8 7 0}$ & 90 & Maddison & 72 & Maddison & 67 & van Zanden & $\mathbf{4 6}$ \\
$\mathbf{1 8 9 0}$ & 52 & Maddison & 50 & Maddison & 76 & van Zanden & $\mathbf{3 6}$ \\
$\mathbf{1 9 1 0}$ & 90 & Maddison & 72 & Maddison & 89 & van Zanden & $\mathbf{4 5}$ \\
$\mathbf{1 9 2 9}$ & 67 & Maddison & 59 & Maddison & 91 & van Zanden & $\mathbf{4 1}$ \\
$\mathbf{1 9 5 0}$ & 165 & Maddison & 152 & Maddison & 91 & van Zanden & $\mathbf{8 1}$ \\
$\mathbf{1 9 6 0}$ & 165 & Maddison & 152 & Maddison & 97 & van Zanden & $\mathbf{8 6}$ \\
$\mathbf{1 9 7 0}$ & 165 & Maddison & 166 & Maddison & 103 & van Zanden & $\mathbf{9 7}$ \\
$\mathbf{1 9 8 0}$ & $165 / 210$ & Maddison/WDI & 152 & Maddison & $87 / 89$ & van Zanden/SWIID & $\mathbf{7 9} / \mathbf{7 5}$ \\
$\mathbf{1 9 8 5}$ & 210 & WDI & 152 & Maddison & 99 & SWIID & $\mathbf{7 6}$ \\
$\mathbf{1 9 9 0}$ & 212 & WDI & 169 & Maddison & 124 & SWIID & $\mathbf{1 1 3}$ \\
$\mathbf{1 9 9 5}$ & 212 & WDI & 168 & Maddison & 142 & SWIID & $\mathbf{1 2 8}$ \\
$\mathbf{2 0 0 0}$ & 214 & WDI & 168 & Maddison & 150 & SWIID & $\mathbf{1 3 2}$ \\
$\mathbf{2 0 0 5}$ & 214 & WDI & 168 & Maddison & 154 & SWIID & $\mathbf{1 4 0}$ \\
$\mathbf{2 0 1 0}$ & 214 & WDI & 125 & Maddison & 105 & SWIID & $\mathbf{8 5}$ \\
\hline
\end{tabular}

Note: This table shows the number of countries for which population data, GDP per capita data in 1990 PPP, and Gini coefficients are available. The last column shows the number of countries that have data for all of the three variables.

All three inequality concepts that are discussed in the next section - global, within- and between-country income inequality — are normalized by the value of the global variance of 1990 in 1990 PPPs (i.e. around 112 million), in order that the sum of the within-country and betweencountry indices equals the global inequality index number. It is important to note that the 1980 values of the indices that are calculated with the historical or the recent data series are nearly identical (see Figure 1 in Section 3.1). The within-country and the global inequality values are slightly higher when the recent data series is used (by $3.2 \%$ and $1.4 \%$ respectively), and the two data series practically lead to the same between-country inequality value. ${ }^{16}$ This similarity not only allows us to analyse the whole period without the need to take into account a break but also suggests that our results are robust when market Gini coefficients from different sources are used.

\footnotetext{
${ }^{16}$ The recent and the historical series are so identical because (i) both series use the same GDP per capita data (from Maddison), (ii) the population data from Maddison and WDI are very similar, and (iii) the market Gini data from van Zanden et al. (2014) and from the SWIID are also relatively similar in many cases.
} 


\section{The historical development of absolute global inequality}

\subsection{Absolute market income inequality}

The solid lines in Figure 1 show that absolute global market income inequality has grown continuously since the start of the industrial revolution, with an especially stark increase after 1950. In the first one hundred years of our sample the average annual growth rate of absolute global inequality was $3.0 \%$, while it was $4.3 \%$ between 1950 and 2010 . This figure also shows that this growth was driven by both within-country (dashed lines) and between-country inequality (pointed lines).

Figure 1: Evolution of absolute global market income inequality, 1850-2010 (Index; 1 = global variance of 1990)

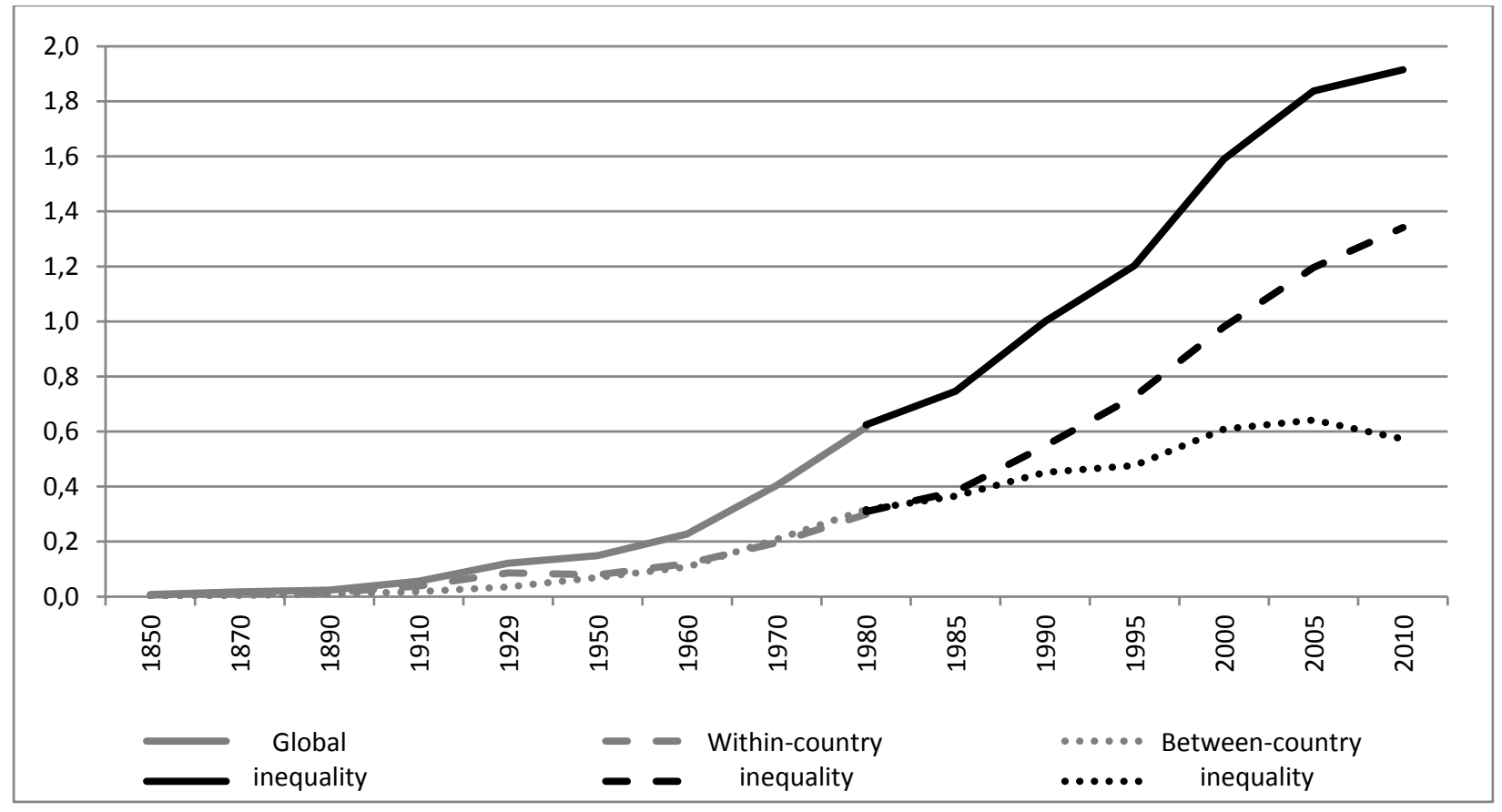

Note: This figure shows the historic evolution of absolute market inequality for a group of 29 core countries, taking into account GDP per capita in 1990 PPPs. The grey lines show the estimates based on the historical data series and the black lines are calculated with the recent data series (see Table 1 for the data sources).

During the period 1870 to 1970 locational income differences were the most important driver behind the increase in global income differences. In 1870 one-fourth of absolute global inequality was resulting from mean income differences between countries, while this figure rose to around $50 \%$ in 1970 (Figure 2). After 1970 the importance of location started to decrease 
again, with the result that in 2010 location 'only' explained around $30 \%$ of absolute global market inequality.

It is also important to note that for the first time since the beginning of the industrial revolution absolute income convergence between developing and developed countries took place between 2005 and 2010 (Figure 1). Two developments explain this absolute convergence process. On the one hand, many rich countries experienced a decline in their per capita income as a result of the financial crisis of 2008 (e.g. US, UK, Italy, Spain, Denmark, and Ireland); and, on the other hand, many relatively poor and populous countries had relatively high GDP growth rates during this period (e.g. China, Russia, Thailand, Brazil, India and Indonesia).

Figure 2: The composition of absolute global market income inequality, 1850-2010

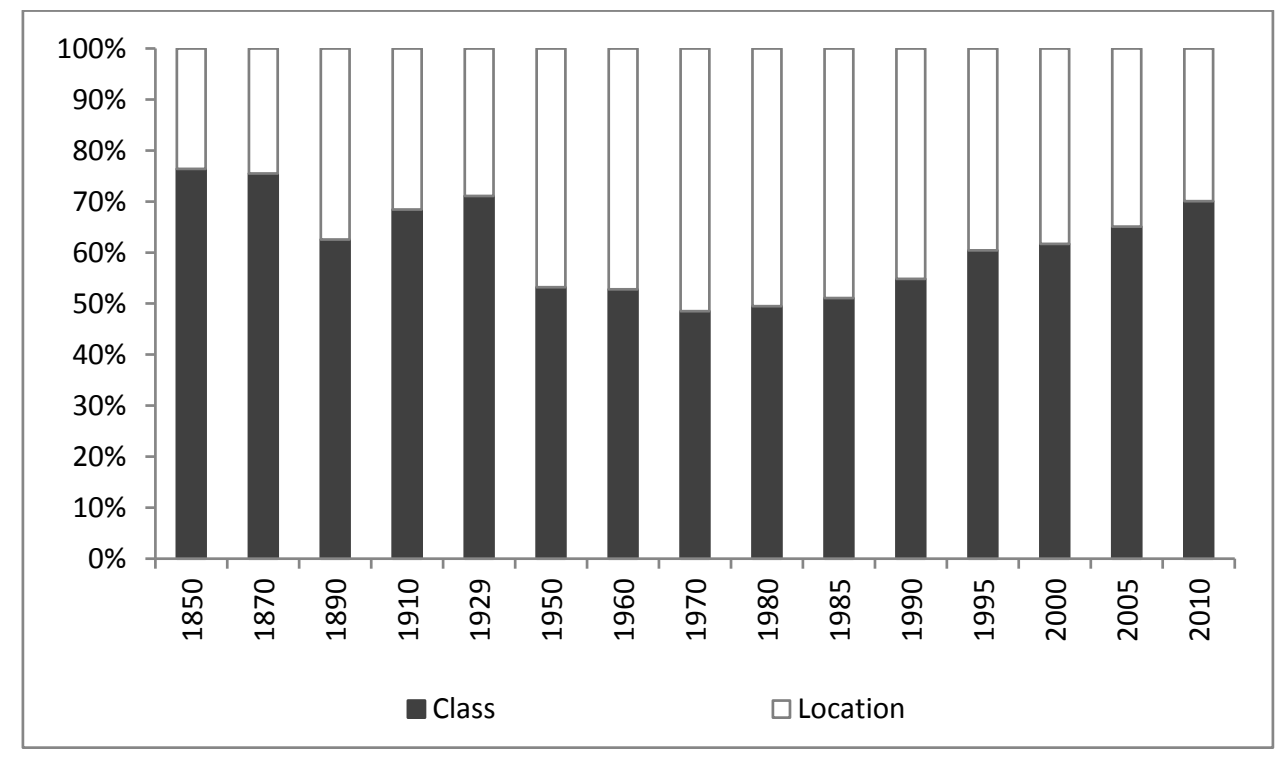

Note: This figure shows how much percent of absolute global market income inequality arose due to income class differences (within-country inequality) and locational income differences (between-country inequality). The 18501970 estimates are based on the historical data series, and the 1980-2010 estimates on the recent data series.

In contrast to between-country inequality, absolute within-country inequality increased especially during the last three decades (Figure 1). To be more precise, between 1980 and 2010 the weight of the within-country component of absolute global inequality increased by around $20 \%$-points, with the result that nowadays around $70 \%$ of global market income differences between individuals can be attributed to inequality between classes (Figure 2). This percentage is similar to that of the beginning of our sample period, where around three-fourths of absolute global inequality is explained by class differences. 
Figure 1 also shows that between 1929 and 1950 absolute within-country inequality decreased (around $-8 \%$ ). The reason for this decrease was a strong decline in relative inequality in most countries -in around $60 \%$ of the core group countries the Gini coefficient declined by more than 5 points. At the same time the average GDP per capita growth was relatively strong (population weighted GDP per capita grew by around 22\% between 1929 and 1950), which means that during this period most of the countries experienced inclusive growth in absolute terms. ${ }^{17}$ This finding is surprising, given that previous studies claim that under normal circumstances absolute inequality will only fall when GDP growth figures are very low or negative (Ravallion, 2004; Anand and Segal, 2014).

All of these findings stand in stark contrast to the conclusions of studies that use relative inequality indices when measuring global market income inequality trends (e.g. Bourguignon and Morrisson, 2002; Milanovic, 2005; 2013; Sala-i-Martin, 2006; Pinkovskiy and Sala-i-Martin, 2009; Piketty, 2014; van Zanden et al., 2014). These studies typically make the following claims: (i) global inequality has grown sharply between 1820 and 1950, and stayed relatively flat or even declined afterwards; ${ }^{18}$ (ii) population weighted between-country inequality increased strongly between the mid of the nineteenth century and the mid of the twentieth century but started to decline afterwards; (iii) within-country inequality registered a downward trend between 1929 and the 1970s and an upward trend afterwards; and (iv) nowadays location differences are much more important to explain global inequality than income class differences. ${ }^{19}$ The discrepancy between our findings and those from relative inequality studies suggests that statements about global inequality should include a clarification if absolute or relative inequality is meant.

\footnotetext{
${ }^{17}$ An obvious caveat in this observation is that two world wars took place during this period.

18 Some studies report a slight increase of global inequality in recent decades (e.g. Milanovic, 2005, 2013; van Zanden et al., 2014), while other studies report a significant decline (e.g. Sala-i-Martin, 2006; Pinkovskiy and Salai-Martin, 2009). See Anand and Segal (2008) and Goda (2013) for an in-depth discussion about the reasons for these inconclusive results.

${ }^{19}$ Van Zanden et al.'s (2014) estimates show that in the year 2000 around $70 \%$ of relative global inequality could be explained by between-country inequality, and Milanovic (2012a, pg.125) finds that nowadays "more than 80 per cent of [relative] global income differences is due to large gaps in mean incomes between countries".
} 


\subsection{Absolute net income inequality}

Given that (especially developed) countries have redistributive policies, absolute withincountry inequality trends could be different when net income shares instead of market income shares are used - net income shares take tax and transfer payments into account. Indeed, Figure 3a shows that absolute net within-country inequality estimates are around 70-80\% lower than that of market inequality. ${ }^{20}$ However, our main interest is the trend change of absolute inequality as the exact value of the variance has little meaning. Figure 3b shows that between 1980 and 1995 absolute market inequality was growing faster than net inequality within countries, whereas afterwards absolute net inequality was growing faster (during the whole period, market income inequality grew around 3.3-fold, while net inequality grew around 3.5-fold). This finding suggests that taxes and/or transfer payments became less progressive after 1995.

Figure 3: Absolute market and net income inequality within countries, 1980-2010

a. Index (1 = global variance of 1990)

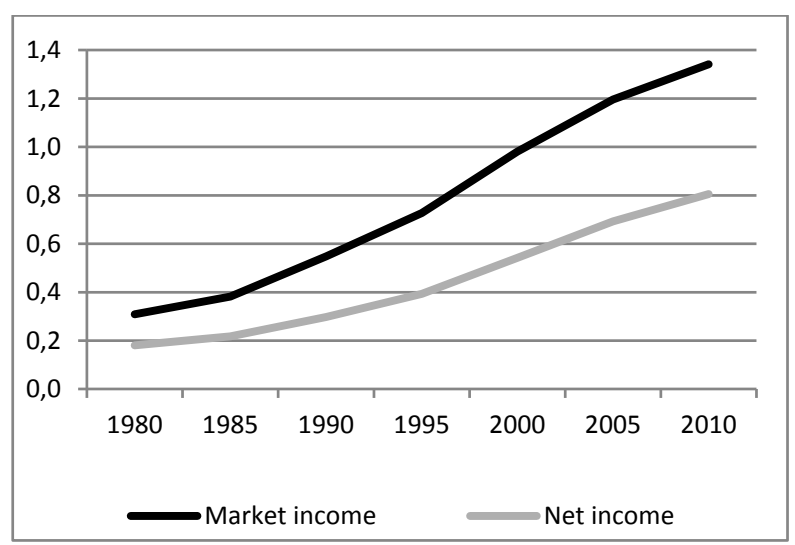

\section{b. Growth rates}

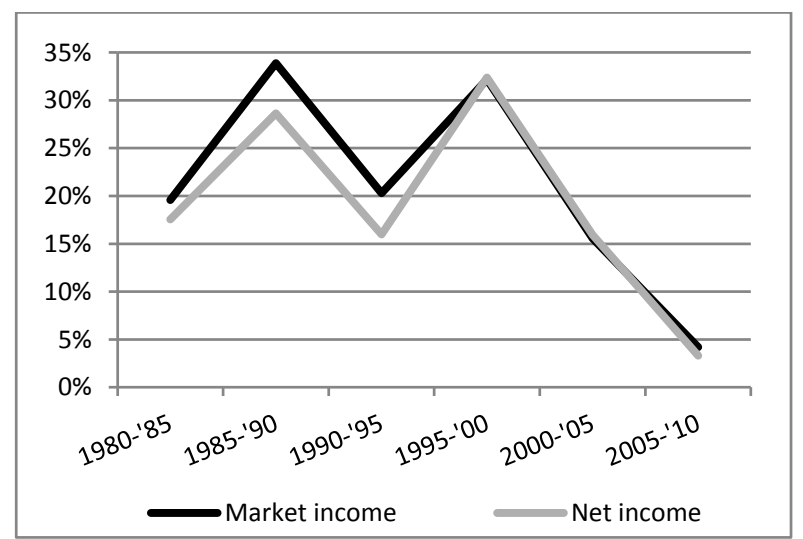

Note: Figure 3 a compares the development of absolute market and net inequality within countries. Both indices are normalized with the value of the global market income variance of 1990 (in 1990 PPPs). Figure 3b shows the 5yearly growth rates of the two indices.

The fact that net within-country inequality is lower than market within-country inequality means that the importance of class differences is lower when absolute global inequality is measured with net income shares. ${ }^{21}$ Accordingly, in 1980 'only' around one-third of global net

\footnotetext{
${ }^{20}$ Net income inequality can only be calculated with the recent data series due to data availability.

${ }^{21}$ Between-country inequality is not affected when net income shares instead of market income shares are used (see part two of Equation 4 in Section 2).
} 
income differences could be attributed to class inequality. However, this figure increased to $58 \%$ in 2010 (Figure 4). The finding that in 2010 class income differences explained most of both absolute global net and market income inequality indicates that redistribution would the most efficient policy option if one would like to reduce the actual levels of absolute global inequality.

Figure 4: The growing importance of class to explain absolute global net inequality

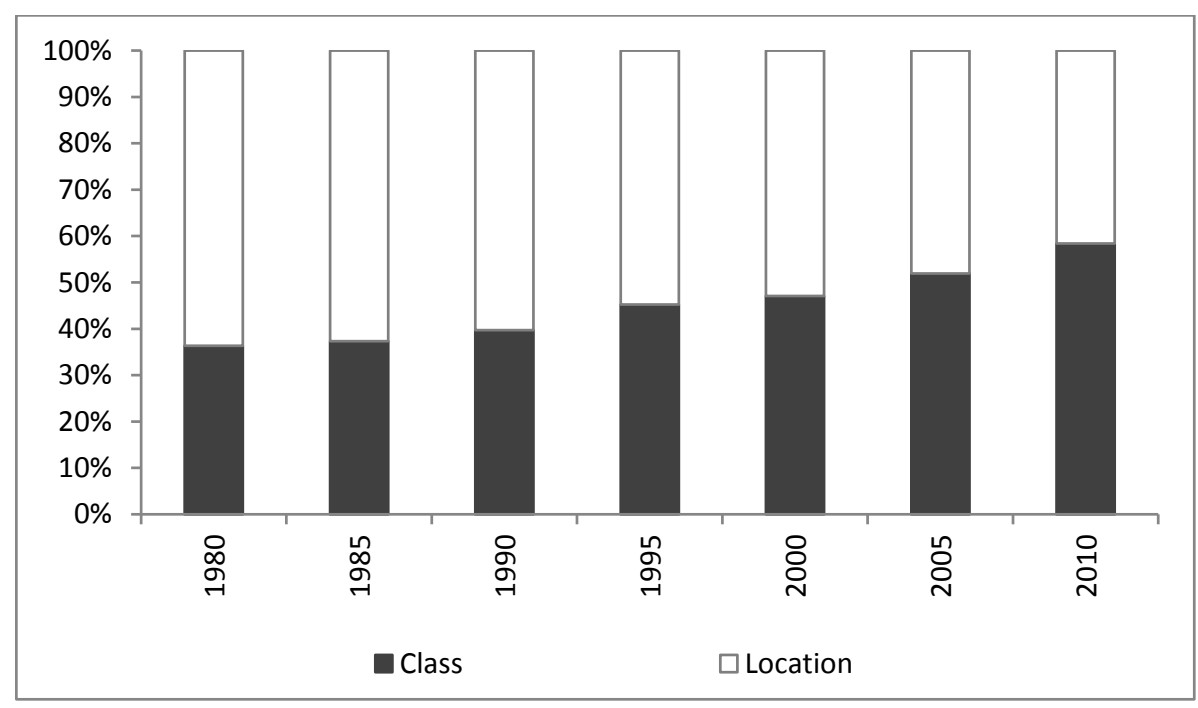

Note: This figure shows how much percent of absolute global net income inequality arose due to income class differences (within-country inequality) and locational income differences (between-country inequality).

\subsection{Robustness of the results}

It is important to check if the estimates change when different PPP exchange rates are used. The impact of PPP exchange rates on absolute inequality is not clear a priori. To our best knowledge, absolute inequality studies have not yet tested for the effect of different PPP exchange rates. Existing relative inequality studies find that estimates that use GDP per capita in 2005 PPP instead of 1990 PPP are higher because the 2005 PPP estimates led to a downward revision of GDP figures in many populous developing countries (Milanovic, 2012b; van Zanden, 2014). We are not aware of global inequality studies that use 2011 PPP exchange rates for their calculations, but Deaton and Aten (2014) find that this new round of PPP estimates is undoing many of the changes of the 2005 round with the results that the "world in 2011 looks sharply more equal than previously calculated" (pg.2). Having said this, the fact that our absolute 
inequality estimates differ significantly from the existing relative estimates suggests that the changes in PPP exchange rates might have different effects in absolute than in relative terms.

Table 2 clearly indicates that the trend changes of within-country, between-country and global inequality are very similar regardless of the PPP exchange rate used. The major differences are that (i) with 2005 PPP the increase of within-country and global inequality is less steep between 2005 and 2010 (in fact it is nearly zero when net Gini coefficients are used), and (ii) the estimates that are based on 2011 PPP exchange rates are, on average, around 10\% higher than those calculated with 1990 PPP. The latter finding is surprising, given that the 2011 PPP round is expected to lead to lower relative inequality figures (as mentioned above). The reason for why the 2011 PPP exchange rates lead to higher absolute inequality is that the latest PPP round resulted in an upward revision of the GDP of many rich countries, which, on average, was higher in absolute terms than the upward revision of poor countries' GDP.

As last robustness check, we are estimating the change in absolute global inequality with the full unbalanced sample. The results suggest that the values and the trend changes are very similar irrespective of whether the unbalanced sample (Figure 5) or the balanced sample (Figure 1) is used. The main distinction is that the unbalanced sample does not show an absolute convergence process between 2005 and 2010. This distinction might arise from the inclusion/exclusion of different countries in different years in the unbalanced sample. We therefore estimate betweencountry inequality for a balanced sample of 160 countries - including many African countriesfor the years 1980 to 2010 (i.e. we estimate only the second part of Equation 4). ${ }^{22}$ The results of this exercise confirm our finding of absolute convergence. To be more precise, these estimates demonstrate that absolute income differences between countries decreased by around 5\% between 2005 and 2010 (Figure 6). ${ }^{23}$

\footnotetext{
${ }^{22}$ For this calculation only GDP per capita and population data are needed, which are available for many more countries in each year than the Gini coefficients.

${ }^{23}$ This finding is in line with Bosmans et al. (2014) results. Bosmans et al. show that absolute between-country inequality increased during the period 1980 to 2009. However, they only find evidence for an increase between 1980 and 2005, while their estimates suggest that absolute inequality decreased afterwards.
} 
Table 2: The evolution of absolute market and net income inequality on a global scale

\begin{tabular}{|c|c|c|c|c|c|c|c|c|c|}
\hline & \multicolumn{9}{|c|}{ Market income inequality index } \\
\hline & \multicolumn{3}{|c|}{1990 PPP } & \multicolumn{3}{|c|}{2005 PPP } & \multicolumn{3}{|c|}{2011 PPP } \\
\hline & Intra-country & Inter-country & Global & Intra-country & Inter-country & Global & Intra-country & Inter-country & Global \\
\hline 1850 & 0.006 & 0.002 & 0.008 & & & & & & \\
\hline 1870 & 0.013 & 0.004 & 0.017 & & & & & & \\
\hline 1890 & 0.015 & 0.009 & 0.023 & & & & & & \\
\hline 1910 & 0.038 & 0.018 & 0.056 & & & & & & \\
\hline 1929 & 0.086 & 0.035 & 0.121 & & & & & & \\
\hline 1950 & 0.079 & 0.070 & 0.149 & & & & & & \\
\hline 1955 & 0.095 & 0.092 & 0.188 & & & & & & \\
\hline 1960 & 0.120 & 0.108 & 0.228 & & & & & & \\
\hline 1965 & 0.166 & 0.155 & 0.321 & & & & & & \\
\hline 1970 & 0.196 & 0.208 & 0.404 & & & & & & \\
\hline 1975 & 0.247 & 0.248 & 0.495 & & & & & & \\
\hline 1980 & 0.309 & 0.315 & 0.625 & 0.314 & 0.350 & 0.663 & & & \\
\hline 1985 & 0.382 & 0.365 & 0.747 & 0.384 & 0.407 & 0.792 & & & \\
\hline 1990 & 0.548 & 0.452 & 1.000 & 0.553 & 0.511 & 1.065 & 0.598 & 0.517 & 1.115 \\
\hline 1995 & 0.727 & 0.476 & 1.203 & 0.709 & 0.547 & 1.255 & 0.786 & 0.557 & 1.343 \\
\hline 2000 & 0.981 & 0.609 & 1.590 & 0.964 & 0.693 & 1.657 & 1.056 & 0.698 & 1.754 \\
\hline 2005 & 1.196 & 0.641 & 1.838 & 1.133 & 0.752 & 1.885 & 1.236 & 0.755 & 1.992 \\
\hline 2010 & 1.342 & 0.573 & 1.915 & 1.234 & 0.687 & 1.922 & 1.370 & 0.673 & 2.044 \\
\hline \multicolumn{10}{|c|}{ Net income inequality index } \\
\hline & & 1990 PPP & & & 2005 PPP & & & 2011 PPP & \\
\hline & Intra-country & Inter-country & Global & Intra-country & Inter-country & Global & Intra-country & Inter-country & Global \\
\hline 1980 & 0.180 & 0.315 & 0.496 & 0.182 & 0.350 & 0.531 & & & \\
\hline 1985 & 0.217 & 0.365 & 0.583 & 0.218 & 0.407 & 0.625 & & & \\
\hline 1990 & 0.298 & 0.452 & 0.750 & 0.295 & 0.511 & 0.806 & 0.322 & 0.517 & 0.839 \\
\hline 1995 & 0.393 & 0.476 & 0.869 & 0.371 & 0.547 & 0.918 & 0.415 & 0.557 & 0.972 \\
\hline 2000 & 0.542 & 0.609 & 1.151 & 0.505 & 0.693 & 1.199 & 0.572 & 0.698 & 1.270 \\
\hline 2005 & 0.693 & 0.641 & 1.334 & 0.609 & 0.752 & 1.361 & 0.682 & 0.755 & 1.438 \\
\hline 2010 & 0.805 & 0.573 & 1.378 & 0.673 & 0.687 & 1.360 & 0.778 & 0.673 & 1.451 \\
\hline
\end{tabular}

Note: This table shows the estimates for our 29 core group countries. The post-1970 estimates are based on the recent data series. All estimates are normalized with the value of the global market income variance of the year 1990 (in 1990 PPPs) — see Table 1 in Section 2 for the data sources. 
Figure 5: Evolution of absolute global market income inequality, unbalanced sample (Index; base = global variance of 1990)

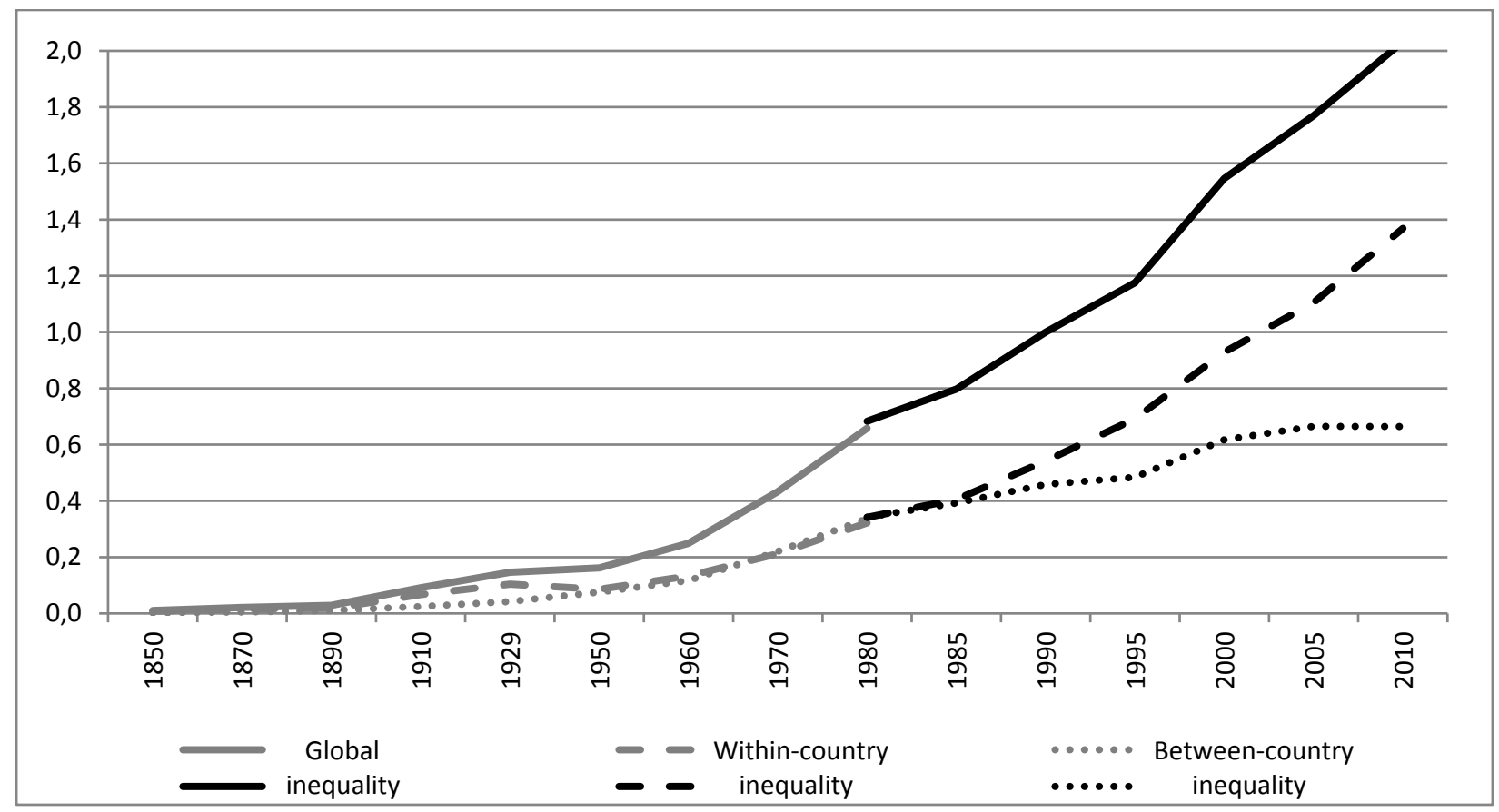

Note: This figure shows the historic evolution of absolute market inequality for the full unbalanced sample. The grey lines show the estimates based on the historical data series and the black lines are calculated with the recent data series (see Table 1 for the data sources).

Figure 6: Absolute between-country inequality estimates for 160 countries (Index, base year 1990)

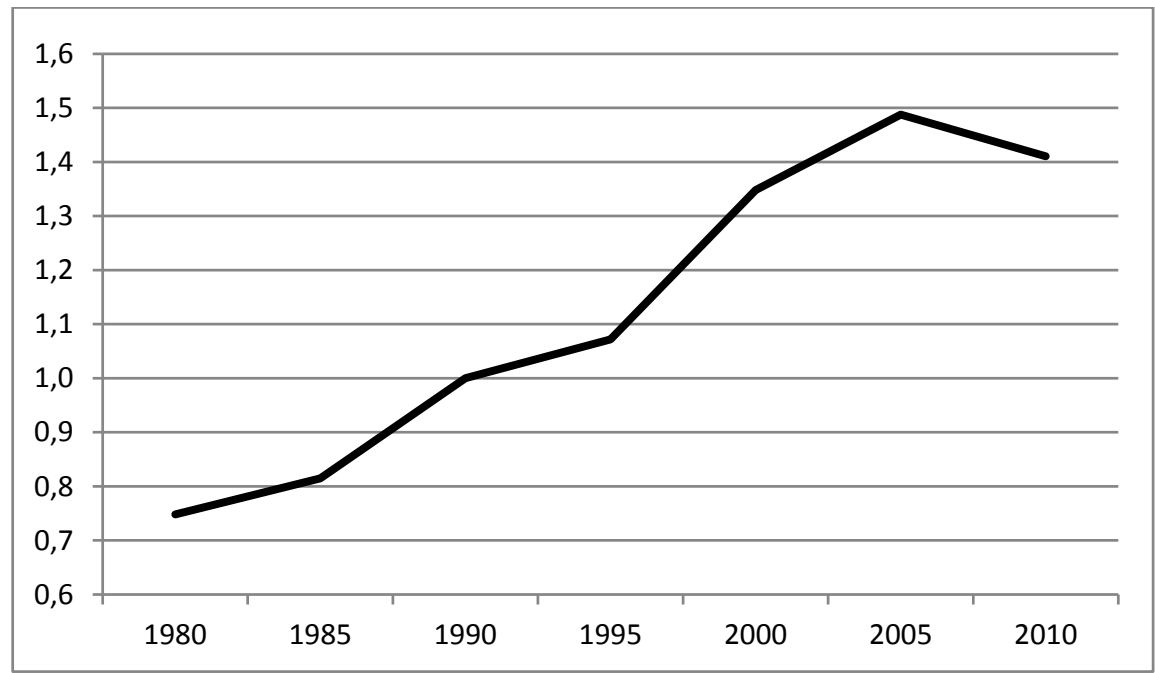

Note: This graph shows the evolution of population weighted between-country inequality for a balanced sample of 160 countries, based on their GDP per capita data in 2005 PPPs from the WDI. 


\section{Conclusions}

This paper examines the historical development of absolute income differences more thoroughly than previously done. The results demonstrate that absolute global inequality has grown continuously since 1850, with an especially stark increase from the middle of the twentieth century onwards. Before 1970 the growth of absolute global inequality was mainly driven by between-country inequality (location), while most of its recent growth can be explained by a sharp increase in within-country inequality (class). In 2010 class differences explained $70 \%$ of absolute global market income inequality, and around $60 \%$ of absolute global net income inequality, which means that nowadays class differences explain nearly as much of global income differences as in 1850 (at least in market income terms).

These findings challenge the often made claims that global inequality has decreased during the last decades (Sala-i-Martin, 2006; Pinkovskiy, and Sala-i-Martin, 2009), and that locational income differences explain most of global inequality (Milanovic, 2012a; 2013). While these claims might be correct with regard to relative income inequality, they are not correct with regard to absolute income inequality. One should therefore abstain from general statements on inequality trends without clarifying if relative or absolute inequality is meant. The same is true for policy advices regarding the reduction of global inequality. At the moment, migration would probably be the best option if on would like to reduce relative inequality, while redistribution would be the most efficient policy option to reduce absolute inequality.

Additional novel findings of this paper are that (i) it is possible to reduce absolute inequality and to grow at the same time when countries initially have high levels of relative inequality (as it was the case between 1929 and 1950); (ii) net inequality within countries was growing faster than market inequality after 1995, which suggests that taxes and/or transfers became less progressive; and (iii) the financial crisis of 2007-09 contributed to an absolute convergence of income between developing and developed countries (for the first time since the industrial revolution). All of these findings are robust when different PPP exchange rates are used. 


\section{References}

Acemoglu, D. and Robinson, J.A. (2008). Persistence of Power, Elites, and Institutions. American Economic Review, 98(1): 267-93.

Amiel, Y. and Cowell, F.A. (1999). Thinking about inequality: Personal judgment and income distributions. Cambridge: Cambridge University Press.

Anand, S. and Segal, P. (2008). What Do We Know about Global Income Inequality?. Journal of Economic Literature, 46(1), pp. 57-94.

Anand, S. and Segal, P. (2014). 'The Global Distribution of Income'. Oxford Department of Economics Discussion Paper, No. 714.

Ballano, C. and Ruiz-Castillo, J. (1993). Searching by questionnaire for the meaning of income inequality. Revista Español de Economía, 10(2): 233-259.

Bosmans, K., Decancq, K. and Decoster, A. (2014). The Relativity of Decreasing Inequality Between Countries. Economica, 81(322): 276-292.

Bourguignon, F. and Morrisson, C. (2002). Inequality among World Citizens: 1850-1992. American Economic Review, 92(4): 727-44.

Breton, T. and García, J.J. (2015). ICP 2005 Construction Prices: Are They Underestimated in Developing Countries?. Review of Income and Wealth, DOI: 10.1111/roiw.12170.

Chakravarty, S.R. (2001). The variance as a subgroup decomposable measure of inequality. Social Indicators Research, 53(1): 79-95.

Chakravarty, S.R. and Tyagarupananda, S. (2009). The subgroup decomposable intermediate indices of inequality. Spanish Economic Review, 11(2): 83-97.

Deaton, A. and Aten, B. (2014). 'Trying to understand the PPPs in ICP 2011: Why are the results so different?'. NBER Working Paper, No. 20244.

Deaton, A. and Heston, A. (2010). Understanding PPPs and PPP-Based National Accounts. American Economic Journal: Macroeconomics, 2(4): 1-35.

Dikhanov, Y. and Ward, M. (2002). 'Evolution of the Global Distribution of Income in 197099'. Fourth Meeting of the Expert Group on Poverty Statistics, Rio de Janeiro, 15-17 October.

Ehrlich, I. (1973). Participation in illegitimate activities: a theoretical and empirical investigation. Journal of Political Economy, 81(3): 521-65.

Esteban, J. and D. Ray (2006). Inequality, Lobbying, and Resource Allocation. American Economic Review, 96(1): 257-79.

Fleisher, B.M. (1966). The effect of income on delinquency. American Economic Review, 56(1/2): 118-37.

Froud, J., Johal, S., Haslam, C. and Williams, K. (2001). Accumulation under conditions of inequality. Review of International Political Economy, 8(1): 66-95.

Gilens, M. and Page, B.I. (2014). Testing Theories of American Politics: Elites, Interest Groups, and Average Citizens. Perspectives on Politics, 12(3): 564-81. 
Goda, T. (2013). 'Changes in income inequality from a global perspective: an overview'. PKSG Working Paper, No. 1303.

Goda, T. and Lysandrou, P. (2014). The contribution of wealth concentration to the subprime crisis: a quantitative estimation. Cambridge Journal of Economics, 38(2): 301-27.

Halter, D., Oechslin, M. and Zweimüller, J. (2014). Inequality and growth: the neglected time dimension. Journal of Economic Growth, 19(1): 81-104.

Harrison, E. and Seidl, C. (1994). Perceptional inequality and preferential judgments: An empirical examination of distributional axioms. Public Choice,79(1-2): 61-81.

Herzer, D. and Vollmer, S. (2012). Inequality and growth: evidence from panel cointegration. Journal of Economic Inequality, 10(4): 489-503.

Herzer, D. and Vollmer, S. (2013). Rising top incomes do not raise the tide. Journal of Policy Modeling, 35(4): 504-19

Kolm, S.-C. (1976). Unequal Inequalities I. Journal of Economic Theory, 12(3): 416-42.

Krueger, A.B. (2012). 'The Rise and Consequences of Inequality in the United States'. Center for American Progress, Washington D.C., USA, 12 January.

Kumhof, M., Ranciére, R. and Winant, P. (2015). Inequality, Leverage, and Crises. American Economic Review, 105(3):1217-1245.

Lagarde, C. (2013). 'A New Global Economy for a New Generation'. World Economic Forum Annual Meeting 2013, Davos, Switzerland, 23 January.

López, H. and Servén, L. (2006). "A Normal Relationship? Poverty, Growth, and Inequality". World Bank Policy Research Working Paper Series, No. 3814.

Maddison Project (2013). Maddison Project Database, 2013 version. http://www.ggdc.net/maddison/maddison-project/home.htm.

Milanovic, B. (2005). Worlds Apart: Measuring International and Global Inequality. Princeton: Princeton University Press.

Milanovic, B. (2012a). Evolution of global inequality: from class to location, from proletarians to migrants. Global Policy, 3(2):

Milanovic, B. (2012b). Global inequality recalculated and updated: the effect of new PPP estimates on global inequality and 2005 estimates. Journal of Economic Inequality, 10(1): 118.

Milanovic, B. (2013). Global Income Inequality in Numbers: in History and Now. Global Policy, 4(2): 198-208.

Minton Beddoes, Z. (2012). For richer, for poorer. The Economist, print edition, October $13^{\text {th }}$.

Obama, B.H. (2011). 'Remarks by the President on the Economy in Osawatomie, Kansas'. Osawatomie High School, Osawatomie, Kansas, USA, 06 December.

Onaran, O. and Galanis, G. (2014). Income distribution and growth: a global model. Environment and Planning A, 46(10): 2489-513. 
Persson, T. and Tabellini, G. (1994). Is Inequality Harmful for Growth?. American Economic Review, 84(3): 600-21.

Pickett, K. and Wilkinson, R. (2010). The Spirit Level: Why Greater Equality Makes Societies Stronger. London: Penguin.

Piketty, T. (2014). Capital in the Twenty-First Century. Cambridge Mass: Belknap Press of Harvard University Press.

Piketty, T. (2015). Putting Distribution Back at the Center of Economics: Reflections on Capital in the Twenty-First Century. Journal of Economic Perspectives, 29(1): 67-88.

Pinkovskiy, M. and Sala-i-Martin, X. (2009). 'Parametric Estimations of the World Distribution of Income'. NBER Working Paper, No. 15433.

Pritchett, L. (1997). Divergence, Big Time. Journal of Economic Perspectives, 11(3), pp. 3-17.

Sala-i-Martin, X. (2006). The world distribution of income: falling poverty and ... convergence, period. Quarterly Journal of Economics, 71(2): 351-97.

Sen, A. (2000). Social Justice and the Distribution of Income. In Atkinson, A.B. and Bourguignon, F. (eds.): Handbook of Income Distribution. Amsterdam: Elsevier, 60-85.

Shorrocks, A.F. (1980). The class of additively decomposable inequality measures. Econometrica, 48(3): 613-25.

Solow, R. (2014). Correspondence: The One Percent. Journal of Economic Perspectives, 28(1): 243-44.

Solt, F. (2009). Standardizing the World Income Inequality Database. Social Science Quarterly, 90(2): 231-42.

Solt, F. (2013). The Standardized World Income Inequality Database, Version 4.0. http://myweb.uiowa.edu/fsolt/swiid/swiid.html.

Soltow, L. (1998). The Measures of Inequality. In Soltow, L. and van Zanden, J. L. (eds.): Income \& Wealth Inequality in the Netherlands 16th-20th Century. Amsterdam: Het Spinhuis, $7-22$.

Stiglitz, J.E. (2012). The price of inequality. London: Penguin Books.

Svedberg, P. (2004). World Income Distribution: Which Way?. Journal of Development Studies, 40(5): 1-32.

van Zanden, J.L., Baten, J., Foldvari, P. and van Leeuwen, B. (2014). The Changing Shape of Global Inequality 1850-2000: Exploring a new dataset. Review of Income and Wealth, 60(2): 279-97. 


\section{Appendix}

\section{The goodness of fit of the income share estimation methodology used}

To check the robustness of our method to derive income shares (Equations 5-6 in Section 2), we calculate income shares with Gini coefficients from the WDI database and compare these estimates with readily available income share data from the same database. WDI reports Gini coefficients and quintile income shares for 155 countries. The available data are very unbalanced ( 881 out of 5,115 possible observations between 1980 and 2012), we therefore use a benchmark year methodology (see Footnote 12) to calculate income shares for the years 1985, 1990, 1995, 2000, 2005 and 2010 (352 out of 930 possible observations).

Table A1 shows that the correlation between WDI's readily available income shares and our estimated shares is close to one (with the exception of Quintile 4), and Table A2 demonstrates that the average difference between the values of our estimated shares and the readily available shares is relatively small. However, our methodology consistently underestimates the two bottom quintile shares, overestimates the shares from Quintile 3 and 4, and underestimates the top quintile share. To check if this difference has an impact on the level and/or trend of absolute inequality estimates, we calculate the level of absolute within-country inequality for a core group of countries ${ }^{24}$ (66 observations) for which WDI quintile share and Gini data are available in each benchmark year.

Figure A1 shows that the correlation between these two inequality series is very close to one. This result suggests that our method produces income share estimates that overall fit the 'real' data very well and that they do not influence trend changes. It is important to note, that the calculated shares lead to a slightly higher level of absolute inequality (around 1\%) than the readily available WDI shares. This means that our income share estimation methodology might lead to a slight overestimation of absolute inequality levels.

24 Argentina, Bangladesh, Brazil, China, Costa Rica, Dominican Republic, Honduras, Indonesia, Philippines, Poland, Tunisia. 
Table A1: Correlation matrix of the calculated and the original income shares

\begin{tabular}{|lccccc|}
\hline & $\boldsymbol{x} \_Q 1$ & $\boldsymbol{x} \_Q 2$ & $\boldsymbol{x} \_Q 3$ & $\boldsymbol{x}_{-} \mathbf{}$ 4 & $\boldsymbol{x}$ _Q5 \\
WDI_Q1 & 0.96 & 0.96 & 0.95 & 0.85 & -0.96 \\
WDI_Q2 & 0.99 & 0.99 & 0.99 & 0.91 & -0.99 \\
WDI_Q3 & 0.96 & 0.98 & 0.98 & 0.93 & -0.98 \\
WDI_Q4 & 0.75 & 0.79 & 0.81 & 0.83 & -0.80 \\
WDI_Q5 & -0.98 & -0.99 & -0.99 & -0.93 & 1.00 \\
\hline
\end{tabular}

Note: The first column refers to the reported quintile shares from the WDI database and the first row refers to our calculated income shares.

Table A2: Average differences between the calculated and the original income shares

\begin{tabular}{|cccccccc|}
\hline & & $\mathbf{1 9 8 5}$ & $\mathbf{1 9 9 0}$ & $\mathbf{1 9 9 5}$ & $\mathbf{2 0 0 0}$ & $\mathbf{2 0 0 5}$ & $\mathbf{2 0 1 0}$ \\
\hline \multirow{2}{*}{ Q1 } & calculated & 0.059 & 0.055 & 0.053 & 0.056 & 0.055 & 0.057 \\
& original & 0.062 & 0.058 & 0.058 & 0.059 & 0.060 & 0.062 \\
\cline { 2 - 8 } & Difference & -0.003 & -0.003 & -0.005 & -0.003 & -0.005 & -0.005 \\
& & & & & & & \\
Q2 & calculated & 0.103 & 0.098 & 0.097 & 0.100 & 0.099 & 0.101 \\
& original & 0.104 & 0.100 & 0.099 & 0.102 & 0.101 & 0.103 \\
\cline { 2 - 8 } & Difference & -0.001 & -0.002 & -0.002 & -0.002 & -0.002 & -0.002 \\
& & & & & & & \\
Q3 & calculated & 0.151 & 0.145 & 0.145 & 0.147 & 0.147 & 0.149 \\
& original & 0.149 & 0.145 & 0.143 & 0.146 & 0.145 & 0.147 \\
\cline { 2 - 8 } & Difference & 0.002 & 0.000 & 0.002 & 0.001 & 0.002 & 0.002 \\
& & & & & & & \\
Q4 & calculated & 0.223 & 0.220 & 0.220 & 0.220 & 0.221 & 0.223 \\
& original & 0.215 & 0.212 & 0.209 & 0.212 & 0.209 & 0.212 \\
\cline { 2 - 8 } & Difference & 0.008 & 0.008 & 0.011 & 0.008 & 0.012 & 0.011 \\
& & & & & & & \\
\multirow{2}{*}{ Q5 } & calculated & 0.464 & 0.483 & 0.485 & 0.476 & 0.479 & 0.470 \\
& original & 0.469 & 0.486 & 0.491 & 0.480 & 0.485 & 0.476 \\
\hline Observations & Difference & -0.005 & -0.003 & -0.006 & -0.004 & -0.006 & -0.006 \\
\hline
\end{tabular}

Note: The first row of each quintile share reports our calculated mean income share, the second row shows the mean income share reported by WDI, and the third row shows the differences between our calculated share and the reported share. 
Figure A1: Absolute within-country inequality estimates based on the WDI data (Index, base year 1990)

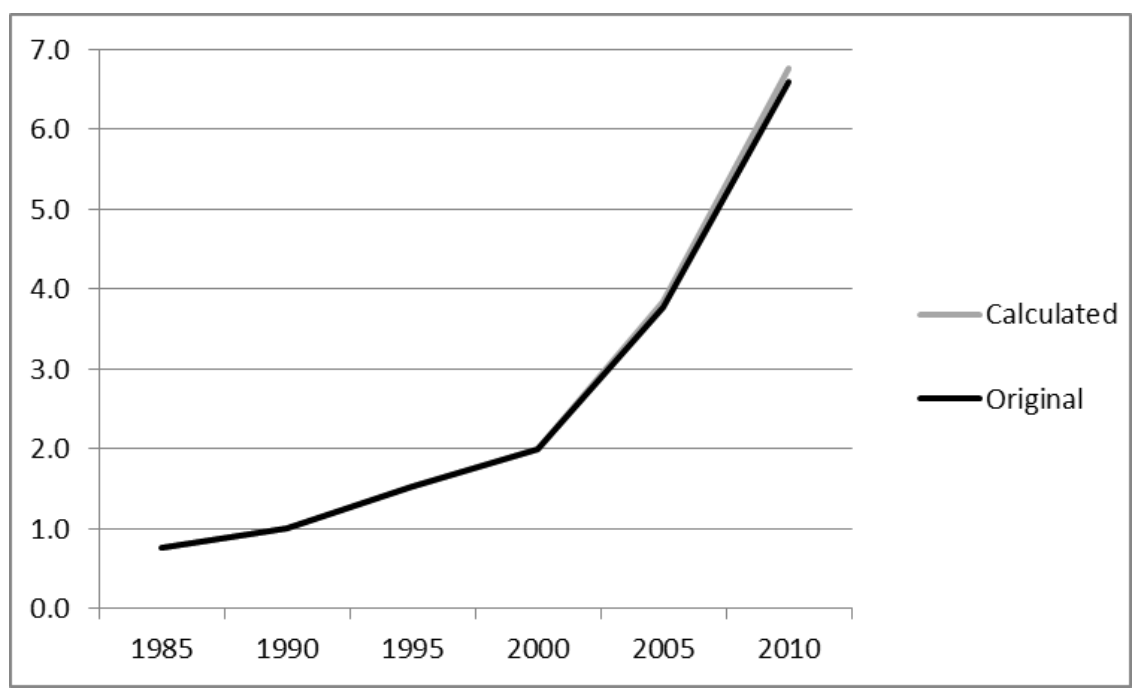

Note: This graph shows absolute within-inequality estimates based on the calculated and the original WDI income shares for those 11 countries for which data are available in each year. 


\section{Overview about data imputations made}

To prevent that imputations affect our main findings, we have not imputed more than two years of data per variable and country. For the imputation of GDP per capita we have used regional averages because this approach is widely used in the existing literature (see e.g. Sala-iMartin, 2006). Please see Table A3 for an overview of the imputations made.

Table A3: Overview of the data imputations made for core group countries

\begin{tabular}{|c|c|c|c|c|}
\hline \multirow{2}{*}{ Country } & \multirow{2}{*}{ Missing years } & \multicolumn{3}{|c|}{ Short description of imputation method } \\
\hline & & GDP per capita & Population & Gini coefficient \\
\hline Colombia & 1850 & & & $\begin{array}{l}\text { Country's Gini coefficient in } \\
1870 \text { adjusted with the growth } \\
\text { rate of Argentina's, Chile's and } \\
\text { Peru's Gini coefficients } \\
\text { between } 1850-1870 .\end{array}$ \\
\hline Ireland & 1850,1890 & $\begin{array}{l}\text { Country's GDP per capita of } \\
1870 \text { adjusted with the region's } \\
\text { growth rate between } 1850 \text { - } \\
1870 \text { and between } 1870-1890 .\end{array}$ & & \\
\hline Peru & 1850 & $\begin{array}{l}\text { Country's GDP per capita of } \\
1870 \text { adjusted with the region's } \\
\text { growth rate between } 1850 \text { - } \\
1870 .\end{array}$ & & \\
\hline Philippines & 1850,1890 & $\begin{array}{l}\text { Country's GDP per capita of } \\
1870 \text { adjusted with the region's } \\
\text { growth rate from } 1850-1870 \\
\text { and from } 1870-1890 .\end{array}$ & & \\
\hline Poland & 1850 & $\begin{array}{l}\text { Country's GDP per capita of } \\
1870 \text { adjusted with the region's } \\
\text { growth rate between } 1850 \text { - } \\
1870 .\end{array}$ & & \\
\hline Russia & $\begin{array}{l}1850,1870 \\
1910\end{array}$ & $\begin{array}{l}\text { Country's GDP per capita of } \\
1890 \text { adjusted with the region's } \\
\text { growth rate between } 1870- \\
1890 \text { and between } 1850-1870 \text {. }\end{array}$ & $\begin{array}{l}\text { The population size from } 1913 \\
\text { was taken for the year } 1910 .\end{array}$ & \\
\hline Switzerland & 1850 & $\begin{array}{l}\text { Country's GDP per capita of } \\
1870 \text { adjusted with the region's } \\
\text { growth rate between } 1850 \text { - } \\
1870 .\end{array}$ & & \\
\hline Thailand & 1850 & $\begin{array}{l}\text { Country's GDP per capita of } \\
1820 \text { adjusted with the region's } \\
\text { growth rate between } 1820 \text { - } \\
1850 .\end{array}$ & & \\
\hline
\end{tabular}

Note: This table shows all imputations that we have made to increase the size of our core country group to 29 countries. 